\title{
The physician's voice in the health care debate
}

\begin{abstract}
Physicians in the United States have a unique appreciation of the tremendous successes and even greater potential of our health care system, yet we also endure firsthand its woeful deficiencies. In the ongoing debate about how to improve the current health care structure in the United States, our individual voices have been all too quiet. No single health care organization, nor its spokesmen, speaks for the broad range of physicians' opinions. Rather, doctors must make every effort, and indeed have an obligation, to speak forcefully as informed participants in this important process.
\end{abstract}

The current health care infrastructure is replete with problems: over 40 million Americans currently have no health insurance, and many others have limited access to care. An ever-increasing proportion of the physician's time is spent navigating reimbursement regulations, leaving fewer precious minutes for patient contact. The current model of medicine, in which the business practices of third-party insurers and hospitals reinforce the need for profitability and stress policies that maximize margins, is discouraging the next generation of caregivers. Easily treatable and preventable diseases fester, resulting in unnecessary costs, pain, and suffering. The physician's ability to control the delivery of care and to emphasize compassionate healing has been diminished and diluted with competing interests. Nearly every physician, in addition to most patients who have entered the medical system with a serious illness, will agree that we can do better, not only in terms of containing costs but also in the realm of delivering care.

Within this context, a curious debate has erupted on the national scene in response to President Obama's mandate for health care reform. Disconcertingly, the voice of the American physician, perhaps all too accustomed to a lack of influence, has barely been heard. Town meetings and public forums have showcased politicians engaging irate citizens on both sides of the issues. Health care insurers and the pharmaceutical industry have invested millions to influence the debate, and a natural tendency to resist change and to fear government intervention has been loudly voiced. Somehow, a desire to reform both the cost and the delivery of health care has been reinterpreted by some as akin to an attempt to restrict the possession of guns or to change the guidelines of legal immigration. These irrational and emotional reactions have clouded the truth that confronts every physician on daily rounds: we can do better.

Despite the increasingly corporate nature of American medicine, people still trust their doctors. Physicians in the community and in academia have a responsibility to provide a fact-based framework for the current debate by disseminating accurate and rational information to their patients and their colleagues. Too much of the public discussion has been inaccurate - or frankly misrepresented - preying on the fears and pride of the American populace. The complexities of delivering quality care and the inequities in calculating costs continue to be opaque to the consumer. The physician is unique in possessing the knowledge, authority, and credibility to explain these issues simply and dispassionately; it is urgent that he/she does so while still enjoying the trust of patients.

Providing universal care is expensive, but many do not understand that society has already been paying an unnecessarily heavy price for health care to the uninsured. There is a pervasive myth that shared responsibility for the cost of health care represents a radical change in policy, when in fact this has long been the case. By acknowledging this reality, we can move forward to design an efficient, cost-effective system in which the economic burden is distributed equitably. For example, by increasing access to preventive care and appropriate early intervention, we can move service for the uninsured out of the emergency room, one of the most expensive health care delivery vehicles. The cost extends beyond dollars, as our emergency system becomes choked by treatment of the uninsured, while those with true emergencies wait long hours for care that should be delivered promptly.

Americans long ago acknowledged that access to education for all citizens benefits individuals as well as society. Few would argue that the existence of our public school system and public colleges threatens private schools. Rather, an accessible and affordable public education system empowers all Americans, strengthens our country, and is simply the right thing to do. Likewise, the provision of appropriate medical care to all
Americans is justified on both pragmatic and moral grounds. Health care reform that improves access to caregivers, that minimizes the dollars and minutes spent on forms, regulations, and administration, and that maximizes time with the doctor and delivery of care must be prioritized.

In an era of untenable cost escalation in our medical system, it is incumbent on physicians, who understand the nuances of care delivery, to participate in a discussion regarding how resources should be allocated. We feel strongly that physicians' time spent discussing care alternatives with ill patients should not be discouraged or misrepresented by political activists. Not only could thoughtful discussions with patients about what medical interventions they desire decrease expenses, but they can help to provide personalized and compassionate care.

Some may argue that changes to the health care system could make matters worse, that we should follow the maxim "primum non nocere" (first, do no harm). In fact, many believe that the US health care system is the best in the world and that any tinkering could only result in making an outstanding process less effective. Let us not fool ourselves. It is essential that this premise be examined rigorously as the debate about health care reform moves forward. While it is certainly true that by metrics such as the availability of the most innovative, novel therapies, the US health care system is indeed second to none, when other, arguably more appropriate metrics such as longevity and childhood mortality are applied, care in the richest nation in the world falls far short. As physicians, we are obliged to intervene to relieve suffering and distress whenever possible. We believe that this commands participation in an honest appraisal of the health care system in which we practice.

We realize that there are many facets to this debate, and that we have aired but a few opinions. The JCI invites comment on the health care debate from all readers and will publish as many contributions in print or online as possible through a forum on our website at www.jci.org. Please send us your thoughts at editors@the-jci.org.

Jonathan A. Epstein, Laurence A. Turka, Morris Birnbaum, and Gary Koretzky 